\title{
A PERPETUAÇÃo DA TESE "LEGítIMA DEFESA DA HONRA" EM CASOS DE VIOLÊNCIA CONTRA MULHER NO ESTADO DE SÃO PAULO
}

\author{
Raphael Allan de Oliveira Soares ${ }^{1}$ \\ Laís Aparecida Batista de Sousa ${ }^{2}$ \\ Micaela Aparecida dos Santos Landim ${ }^{3}$ \\ Thais Ribeiro de Sousa ${ }^{4}$ \\ Maurício Martins Alves ${ }^{5}$ \\ Luiz Carlos Andrade de Aquino ${ }^{6}$ \\ Daniel Lipparelli ${ }^{7}$
}

\begin{abstract}
Resumo: O artigo tem por objetivo caracterizar a tese "legítima defesa da honra" utilizada em casos de violência contra a mulher, verificar como tal tese tem aparecido nos tribunais do Estado de São Paulo, e principalmente verificar como o Poder Judiciário estadual tem lidado com uma tese enraizada no machismo. Baseando-se em pesquisa literária e pesquisa de jurisprudências no site do Tribunal de Justiça de São Paulo, conclui-se que tal argumento ainda hoje se faz presente nos tribunais paulistas, e que em poucos casos o judiciário se mostra tão machista quanto a tese apresentada pela defesa. Tal conclusão pode nos mostrar o caráter machista, ainda que em declínio, do Tribunal de Justiça do Estado de São Paulo.
\end{abstract}

Palavras-chave: Legítima defesa; Honra; Violência; Mulher.

\footnotetext{
${ }^{1}$ Direito/Univap, Brasil. E-mail: raphaael.allan@gmail.com.

2 Direito/Univap, Brasil. E-mail: laisbatista.sousa@gmail.com.

3 Direito/Univap, Brasil. E-mail: micaelasantos158@gmail.com.

4 Direito/Univap, Brasil. E-mail: thais_r.sousa@hotmail.com.

5 Direito/Univap, Brasil. E-mail: mmalves@univap.br.

6 Direito/Univap, Brasil. E-mail: aquino@univap.br.

7 Direito/Univap, Brasil. E-mail: fernandez@univap.br.
} 